http://dx.doi.org/10.5007/2175-7968.2014v1n33p325

\title{
SIMPSONS - EPISÓDIO BART OF DARKNESS: UMA JANELA INDISCRETA PARA O CORAÇÃO DAS TREVAS
}

Brunilda T. Reichmann*

Julián Bargueño**

\begin{abstract}
Resumo: Este artigo tematiza diálogos intertextuais motivados pelo romance de Joseph Conrad, Heart of Darkness. A obra inspirou o instigante episódio Bart of Darkness do seriado Os Simpsons, além de haver dado origem a um filme homônimo e a outra transposição fílmica, intitulada Apocalypse Now. Para discutir essa rede de relações entre obras foram utilizadas abordagens teóricas propostas por Gérard Genette (2003) e Leyla Perrone-Moisés (1978), além de estudos sobre adaptação de Brian McFarlane (1996).
\end{abstract}

Palavras-chave: Bart of Darkness. Os Simpsons. Heart of Darkness. Apocalypse Now.

\section{SIMPSONS - EPISODE BART OF DARKNESS: A REAR WINDOW TO THE HEART OF DARKNESS}

\footnotetext{
* Doutorado em Letras pela University of Nebraska in Lincoln (UNL). Pós-Doutorado pela Universidade Federal de Minas Gerais (UFMG). Professora do Mestrado em Teoria Literária do Centro Universitário Campos de Andrade - UNIANDRADE, PR. Curitiba, Paraná, Brasil. E-email: brunilda9977@gmail.com

${ }^{*}$ Mestrado em Teoria Literária pelo Centro Universitário Campos de Andrade. Tradutor e Revisor nas empresas Yellow DJ Academy, NORIS - Espaço de Arte, Arauco do Brasil S.A. Curitiba, Paraná, Brasil. E-email: julianbarg@yahoo.com
} 


\begin{abstract}
This article focuses on intertextual relations motivated by the novel Heart of Darkness by Joseph Conrad. The novel has inspired the provoking episode Bart of Darkness from The Simpsons series, besides having given rise to an hononymous fim and to another filmic transposition called Apocalypse Now. In order to discuss this network of relations among texts, theoretical approaches proposed by Gérard Genette (2003) and Leyla Perrone-Moisés (1978), as well as Brian McFarlane's studies on adaptation (1996) have been useful.
\end{abstract}

Keywords: Bart of Darkness. The Simpsons. Heart of Darkness. Apocalypse Now.

Bart of Darkness (1994), um dos episódios de Os Simpsons, criado por Matt Groening, remete o espectador, por seu título, ao romance de Joseph Conrad (1999), Heart of Darkness ${ }^{l}$ que deu origem ao filme homônimo e à transposição fílmica Apocalypse Now (1979). No primeiro filme homônimo, a adaptação prende-se ao romance e à narrativa de Marlow, resgatando sua viagem ao coração do Congo em busca de um dos agentes ingleses, Kurtz, encarregado, de enviar marfim ao governo britânico. A busca por Kurtz torna-se o grande empreendimento de Marlow, narrador que, anos mais tarde, recupera em detalhes essa sua mais impressionante missão ao coração das trevas. No filme Apocalypse Now (1979) há uma transculturação do episódio, ao se adaptar a narrativa de crimes praticados pelo império britânico à narrativa de crimes praticados pelos Estados Unidos na guerra do Vietnã. As falas são as mesmas, a busca é a mesma, o fascínio de Marlow pelo "agente Kurtz" é o mesmo.

Em Apocalypse Now (1979) Kurtz é um oficial estadunidense que enlouquece em sua triste missão de dominar e dizimar um povo estrangeiro, missão semelhante à dos agentes britânicos em solo congolês. Antes de assistir Bart of Darkness (XXXX) a atitude do espectador que conhece o romance de Conrad reside em buscar semelhanças e diferenças que irá encontrar no episódio dos Simpsons, imaginando que Heart of Darkness (CONRAD, 1999) e os filmes que o têm como hipotexto, ou texto-fonte, sejam as fontes 
do episódio de Os Simpsons. Essas expectativas são frustradas, no entanto, porque o episódio não remete o espectador ao romance de Conrad ou às adaptações fílmicas. Ele o remete ao filme cult de Alfred Hitchcock, Janela indiscreta (1954).

Fascinado por histórias de crimes e assassinatos, Hitchcock encontra no conto Rear Window (Rear Window é também o título do filme Janela indiscreta em inglês), de Cornell Woolrich (2005), o material para seu filme. Rear Window havia sido primeiramente publicado com o título It had to be murder ("Tinha que ser assassinato") e assinado por William Irish, pseudônimo de Woolrich. O primeiro título do conto deixa a trama do famoso filme mais explícita. O segundo título, Rear Window, elimina a ideia do assassinato, mas já ao início do conto e do filme instaura o tom de mistério, de questionamentos que permeia as obras, tanto a ficcional como as fílmicas.

Na adaptação de Hitchcock, em Greenwich Village, Nova Iorque, L. B. Jeffries, vulgo "Jeff” (James Stewart), um fotógrafo profissional, impossibilitado de trabalhar por ter quebrado a perna, dedica-se a observar, com um binóculo e a teleobjetiva de sua máquina fotográfica, a vida dos vizinhos do condomínio de classe média baixa onde mora. Como está acostumado a fotografar situações de perigo e tem um humor um tanto cáustico diante da vida, intensificado pela impossibilidade de se locomover e trabalhar, as atitudes de um vizinho faz com que Jeff acredite que o mesmo tenha assassinado a esposa inválida. A princípio criticado por sua noiva, Lisa Carol Freemont (Grace Kelly), passa a ter nela uma aliada para sua versão do assassinato, a partir do momento em que a moça vê, através da janela de Jeff, o vizinho amarrar um grande baú com cordas grossas e despachá-lo. Jeff e Lisa, juntos, tentam de todos os modos provar que o vizinho é um assassino nesse filme do mestre do suspense, Hitchcock. ${ }^{2}$

O conto Rear Window (WOOLRICH, 2005), é o hipotexto do filme Janela Indiscreta (1954), mas Hitchcock trabalha esse hipotexto de modo a torná-lo atraente aos espectadores que, além 
de atraídos pela história de suspense, ficam também fascinados por outras interpolações. As funções cardeais ${ }^{3}$ do conto, como a impossibilidade de movimentar-se do jornalista, sua obsessão em observar os vizinhos e a conclusão de que esse vizinho, cuja esposa é inválida, foi por ele assassinada e o corpo enviado para algum lugar, dentro de um baú, são todas transferidas para o filme. No conto, contudo, o protagonista não está envolvido emocionalmente com uma moça linda, culta e elegante, chamada Lisa (Grace Kelly), nem vizinhos que atiçam a apreciação pela arte, o senso estético, a curiosidade e a libido do espectador - fórmula perfeita para o sucesso do filme.

$\mathrm{O}$ romance entre Jeff e Lisa, apesar da reticência do protagonista quanto às suas intenções e da aparente submissão da moça - relação típica da época em que o homem resiste a "ser fisgado" pela mulher que o ama - insere uma fórmula mágica para agradar o público: um subplot de amor subordinado à história de suspense. Aos vizinhos sem atrativos de Woolrich, Hitchcock inclui: um pianista virtuoso e sua vibrante plateia (amigos que o visitam); uma dançarina que tem um corpo escultural e anda em trajes sumários, passando a maior parte do dia treinando seus passos, ou fazendo exercícios diante da janela aberta e, à noite, ignorando o assédio masculino; recém-casadoss que, ao contrário da narrativa de Woolrich, não estão sempre saindo para "baladas", mas permanecendo no apartamento, com as venezianas fechadas, o que sugere uma intensa vida sexual.

Há, ainda, inserções menos atraentes, como uma mulher deprimida e um casal cuja esposa tem um cachorro. Tais inserções são importantes por motivos diferentes: a primeira é uma mulher com mais idade, sem um "único alento" na vida que, naquela época, significaria ter um homem para fazer-lhe companhia; e a segunda é necessária para que o jardim com a terra remexida pelo cachorro intensifique o suspense do filme.

O casal mais idoso com a mulher inválida - cujo marido é o suposto assassino - funciona como uma "transferência" ${ }^{4}$ do conto. Esses "quadros" emoldurados pela janela do observador Jeff 
podem ser apreendidos como elementos de alternância ${ }^{5}$ nos quais a juventude aparece relacionada à intensidade e ao interesse pela vida, enquanto os personagens com mais idade são apáticos, dependentes e depressivos. No único caso em que a intensidade e a determinação se manifestam em um casal com mais idade, esse fato está relacionado, na mente de Jeff, ao crime.

Bart of Darkness (1994) dos Simpsons estabelece um diálogo tanto com a narrativa de Woolrich (2005) como com o filme de Hitchcock, ambos hipotextos do episódio. Segundo Leyla Perrone-Moisés: "Todo texto é absorção e transformação de uma multiplicidade de outros textos', diz Kristeva, na esteira de Bahktin" (PERRONE-MOISÉS, 1978, p. 63). Ao que Gérard Genette (2003, p. 91) acrescenta que:

\begin{abstract}
A arte de 'fazer o novo com o velho' tem a vantagem de produzir objetos mais complexos e mais saborosos do que os produtos originalmente 'fabricados': uma função nova se mistura a uma estrutura antiga, e a dissonância entre os dois elementos co-presentes dá sabor ao conjunto
\end{abstract}

Pode-se classificar a adaptação de Os Simpsons como dissonante em relação aos seus textos de origem. Assim também poderiam ser classificadas as funções catalizadoras no filme de Hitchcock em relação ao conto de Woolrich, funções estas que estão relacionadas a pequenas ações e complementam ou dão suporte às funções cardeais. Essa dissonância dá sabor à nova produção, aumenta a complexidade de sua leitura, pois não se pode afastar da estrutura anterior ao se ler o novo. Assim se coloca o espectador diante do episódio Bart of Darkness.

Considerando a adaptação de um cult movie e do conto, surgiram hipotextos e intertextos a partir do episódio que serviu de inspiração. Os idealizadores tiveram então que fazer várias escolhas: o conjunto residencial de apartamentos de Greenwich Village (classe média baixa) transforma-se em um condomínio de subúrbio 
(classe média) com casas ao invés de pequenos apartamentos; o desconforto da situação de Jeff (impossibilidade de se locomover) no verão nova iorquino encontra ressonância em situações também desconfortáveis em Os Simpsons, como o excessivo calor do verão, ou crianças em férias sem muita opção de lazer e invadindo a piscina dos outros, ou a impossibilidade de Bart se locomover. A perna quebrada de Bart soa como uma "transferência" da perna quebrada do protagonista do conto de Woolrich e do filme de Hitchcock; o suposto assassino passa de senhor de meia-idade no filme de Hitchcock e no conto de Woolrich a um pacato morador da vizinhança e pai de família, com esposa e dois filhos pequenos.

Apesar de Bart of Darkness (1994) ter como hipotextos tanto o conto de Woolrich (2005) como o filme de Hitchcock, pode-se ainda perceber que há, na relação dessas três obras, uma sequência não apenas temporal, mas quase hierárquica de inserção ou supressão de funções que darão, à adaptação seguinte, novos significados. O filme Janela indiscreta (1954), ao adaptar o conto, insere índices integracionais ${ }^{6}$ específicos, que se tornam referência para a adaptação da obra seguinte, de forma que Bart of Darkness termina por adquirir, em muitos momentos, características que resgatam, originalmente, parte de apenas um dos hipotextos em questão. Percebe-se assim, que não apenas as funções cardeais tomam um papel determinante na concretização de um hipertexto, como ao se adaptar um primeiro hipotexto e transformá-lo em um segundo (como é o caso da relação do conto com o filme de Hitchcock), novas relações se desdobram em que estes novos ajustes ou inserções serão, em um novo hipertexto, transformados em seus significados.

Em Bart of Darkness (1994) tem-se a trama de Janela indiscreta (1954) transposta para um ambiente mais seguro, familiar e conhecido. Lisa, irmã de Bart, em uma clara relação com Lisa, namorada de Jeff, toma seu lugar no enredo ao ser a figura que acompanha Bart ao isolar-se no quarto escuro, tentando aliviá-lo do sofrimento que está sentindo. Suas roupas, o colar de pérolas que usa, ou a eventual cumplicidade com Bart em sua obsessão pelo crime que 
este acredita ter ocorrido remetem também à personagem Lisa, interpretada por Grace Kelly, em Janela indiscreta. Esta adaptação da personagem original de Lisa, que termina por ser determinante no enredo de Bart of Darkness, é possível apenas por se identificar, no filme de Hitchcock, um texto intermediário que, em sua força imagética, termina por apontar para novos pontos principais dentro das relações pessoais que motivam o enredo.

Em se tratando de adaptações de obras conhecidas do público - pela expectativa da comprovação ou negação da obra fonte - a questão da fidelidade é, muitas vezes, motivo de julgamento qualitativo por parte dos espectadores. No caso específico da intertextualidade e da adaptação do filme de Hitchcock para o episódio de Os Simpsons, a própria natureza da mídia de animação cria um movimento contrário, que incita à dúvida, à curiosidade e ao inesperado. Espera-se, portanto, que em uma relação intersemiótica como esta - considerando a linguagem do texto hipertextual ( $O s$ Simpsons) -, exista um componente criativo presente e marcante envolvido. Na perspectiva tradicional de uma adaptação, cria-se a expectativa de que não apenas pontos cruciais, mas também detalhes que individualmente se acredita serem determinantes para uma recepção satisfatória se encaixem para que ambas as obras sejam reconhecidas uma na outra.

Na adaptação de Bart of Darkness, esse movimento se dá de forma alterada, pois o desenho de animação, ao ser veículo de comunicação de massa, já tem, a priori, o poder de sugerir características próprias que precisam ser realizadas para que a linguagem e a recepção da mídia usada se concretizem satisfatoriamente. Dessa forma, a adaptação de Janela indiscreta (1954) e Rear Window (WOOLRICH, 2005) para o episódio de Os Simpsons termina por ser uma fusão entre seletas funções cardeais dos hipotextos e índices integracionais indispensáveis no hipertexto, de forma a manter índices da obra adaptada. Pode-se considerar que fazem parte dessa técnica específica de adaptação não apenas a habilidade de recriação e interpretação ao se buscar conservar funções cardeais dos 
hipotextos, como também a capacidade de sustentar a atmosfera indispensável para a identificação da mídia hipertextual.

A escolha da mídia a ser utilizada em uma adaptação é determinante na linguagem que será usada para expressar o processo de tradução e adequação do hipotexto correspondente. Essa determinação - como é o caso de Bart of Darkness - permite tanto liberdades quanto restrições: em um desenho animado de grande alcance e popularidade, que sugere ambiente, temática, personagens, relacionamentos e padrões comportamentais específicos, os limites dentre os quais se pode e se espera transitar são claros. Apesar de, neste caso, Bart of Darkness ser o hipertexto, o seriado Os Simpsons é um texto por si só, que deve movimentar-se por outros meios. Partindo deste princípio e obedecendo à sua própria estrutura, o episódio pode então incorporar hipotextos de forma a estendê-los, desenvolvendo uma linguagem intertextual única, que funde características fundamentais dos textos envolvidos.

Ao entrar em contato com o episódio de Os Simpsons, que remete a Janela indiscreta e a Rear Window, o espectador não se limita a vivenciar o filme ou o conto de outro ponto de vista apenas, mas sim de um ponto de vista com características familiares, pois ao assistir Os Simpsons, sabe-se, dentro de um perímetro confiável, por onde se está transitando. Da mesma forma que um formato (qualquer que esseja) limita o leitor a permanecer dentro de suas fronteiras de identidade, ao mesmo tempo criam-se, também, na nova mídia, uma série de outras possibilidades que os textos hipotextuais não suportariam.

Em Janela indiscreta (1954), vê-se Jeff sentado em sua cadeira de rodas, de binóculos em punho, irritado, ansioso e obcecado pela possibilidade de que teria havido um assassinato. O filme - assim como o conto - ocorre no que pode ser chamado de "vida real". As obras de Hitchcock e Woolrich (2005) retratam uma realidade semelhante à dos espectadores, que reconhecem, no mundo ficcional das narrativas, o seu próprio mundo, com as mesmas probabilidades e impossibilidades. Ou seja: ao assistir Janela indiscreta 
ou ler Rear Window, reconhece-se que nem o conto nem o filme extrapolaa realidade empírica.

No momento em que existe a busca de transposição dos hipotextos para Bart of Darkness, porém, as possibilidades se abrem e muito do que não seria possível ou aceitável nas obras de origem passará não só a ser cabível, como esperado. Em suas inúmeras convergências com seus hipotextos, o episódio de Os Simpsons não só dialoga de forma original com estes, como estende o diálogo aos limites que sua própria linguagem e mídia lhe permitem. Justamente por ter um formato que favorece o humor - e é esperado que o faça - Bart of Darkness consegue, simultaneamente, rir da suposta tragédia de Janela indiscreta e Rear Window, criticando, de forma irônica, o mundo atual e a natureza humana.

Ao ver seus amigos se divertindo na piscina, Bart, imobilizado pelo gesso e preso no quarto, fecha a cortina e diz: "Traidores, fiquem com sua piscina. Estou bem sozinho. Aqui". (Traitors, go on and have your pool. I'm fine by myself. Right here). Cada vez mais isolado, mal-humorado e ranzinza, ele insiste, quando sua irmã entra no quarto: "Não acenda a luz" (Don't turn on that li$g h t)$. Essas palavras, saindo da boca de um garoto birrento, têm o efeito de divertir o espectador e fazê-lo esperar pela próxima cena, que possa dar continuidade a um épico trapalhão.

Uma situação semelhante em Janela indiscreta - a imobilidade, a dependência da enfermeira e da namorada até para as necessidades básicas, o isolamento - terminam por levar o protagonista do filme a sofrer de uma obsessão que o domina. Neste caso, não são risadas que vêm à cabeça do espectador, mas, em seu lugar, curiosidade, dúvida, questionamento e ansiedade. Essa questão da incapacidade de locomoção e do tédio em uma rotina limitada, somada a uma imaginação fértil e aventureira, toma proporções que levam o personagem Jeff a imaginar um assassinato, em uma clara compensação da mente humana para que seu mundo interior continue a fazer sentido. Limitado a viver em seu próprio espaço, mas com a possibilidade de observar de longe a vida dos que o cercam, este 
estado físico - que se torna também mental - passa então a criar um mundo autocentrado, que parece necessitar de expansão. Ao buscar a inclusão de fatores externos à sua existência, como ouvir o que os vizinhos dizem, ou o que lhes acontece, o que fazem no seu dia-a-dia, Jeff cria um processo de regulagem da própria realidade, possibilitando assim que esta transgrida os limites da condição que se impõe sobre ele.

Ao ampliar essas fronteiras de percepção, o personagem expande também a noção de si próprio que, agora, ao tomar fatores do mundo exterior e apreendê-los como seus, passa a justificar sua existência e motivação perante o que imagina estar se passando ao redor. Bart, por sua vez, ao parodiar esse processo de apropriação do mundo alheio, tem o poder de revelar o quão ridícula pode se tornar a imaginação humana em sua tentativa instintiva de expansão do real. Ao tomar para si uma possível verdade alheia - o assassinato da mulher por seu esposo - e agir conforme esta realidade, a animação ameniza a psicologia humana, que tem como padrão de funcionamento compensar suas incapacidades, imobilidades e restrições, assim apropriando-se dos mínimos indícios e sugestões proporcionadas pelo mundo exterior.

No momento da transposição de seus hipotextos, Bart of Darkness, pelas próprias características da linguagem que utiliza, tem o poder de modificá-los, satirizando questões existenciais presentes no filme e no conto, como o tédio, a solidão, a obsessão e a violência. Ao substituir personagens, questionar funções, inverter sentidos e modificar contextos, o episódio de Os Simpsons permite olhar para os mesmos pontos através de outro enfoque, que não seria possível se tais características não fossem intrínsecas à linguagem do seriado.

Ao mesmo tempo em que aborda, de forma original, as questões recorrentes em Janela indiscreta e Rear Window, Bart of Darkness tem o poder de recriar passagens, que funcionam como referência a pontos principais do enredo. Quando Bart resolve, emburrado, que será mais feliz trancado em seu quarto, no escuro, assistindo 
televisão, do que lá fora na piscina com os amigos - já que não tem opção -, é o início do que será a sua obsessão pelo assassinato que ele acredita ter acontecido. A situação se agrava ainda mais quando seus amigos e parentes parecem se divertir de forma desmedida, saltando e nadando em sincronia ao fundo de uma música de festa, que claramente faz alusão às melodias entoadas nas festas do apartamento vizinho de Jeff, em Janela indiscreta.

Bart, em seu isolamento, assiste a um programa de TV em que uma personagem é presa atrás de uma parede de tijolos e, após ser libertada três mil anos depois, aparece esquartejada, em uma clara alusão ao assassinato em Janela indiscreta, bem como a contos de terror e assassinato de Edgar Alan Poe. ${ }^{7}$ No filme de Hitchcock, a mulher supostamente assassinada pelo marido também teria sido vítima do mesmo método, depois de passar dias na cama, doente. Mas aparece em Os Simpsons, porém, o que não é mostrado no filme ou no conto: a cena do esquartejamento de forma aberta, exagerada e sangrenta. Esta possibilidade de se mostrar explicitamente o esquartejamento permite, dentro dos limites do que para alguns é considerado humor, uma contundente crítica social à recepção da violência no mundo contemporâneo, pois no momento em que a personagem é esquartejada em público, este aplaude entusiasmado, como se estivesse a assistir a um espetáculo.

Em Janela indiscreta, o mundo exterior ao apartamento de Jeff é constantemente observado pela câmera subjetiva ou visto do ponto de vista do protagonista. O espectador do filme, ao testemunhar as atividades dos apartamentos vizinhos, suas particularidades e variações, sob um olhar de parceria com o protagonista, torna-se cúmplice deste com uma curiosidade desmedida, alimentada por um dia-a-dia sem grandes oportunidades. Este processo se quebra, porém, ao se perceber como Hitchcock age de forma a criar um padrão e, mais tarde, ao quebrá-lo sutilmente.

Ao condicionar o espectador a acreditar que o que a câmera lhe mostra é o mesmo que Jeff enxerga - e consequentemente o que o próprio espectador vê através da janela - cria-se um estado confor- 
tável, que mantém a plateia ilusoriamente segura. Momentos mais tarde, porém, percebe-se que em um dos movimentos que sugere um olhar para fora da janela, as expectativas serão quebradas ao final do movimento da câmera objetiva, que termina por mostrar Jeff adormecido na cadeira, evidenciando que a cumplicidade se quebrou: agora, o espectador viu mais do que o protagonista, portanto sabe mais do que ele sobre os outros personagens da trama.

$\mathrm{Na}$ adaptação do enredo de Janela indiscreta para Os Simpsons, este olhar é subvertido. Inicialmente não parece haver qualquer reminiscência da técnica de Hitchcock em Bart of Darkness: a animação corre de formal natural, com a focalização da câmera objetiva em cada ação principal. Pode-se ver a família Simpson dentro da barraca, Bart caindo do trampolim, seus amigos se divertindo e, mais tarde, ao se enxergar Bart engessado, deitado na cama, o enfoque obtido pelo espectador é tanto de um ponto de vista semelhante ao do filme de Hitchcock - de dentro do próprio quarto - como de qualquer um dos convidados que está na piscina e pode ver o garoto no andar de cima da casa, atrás da janela.

Em determinado momento, porém, o espectador é pego de surpresa ao constatar que Bart, através de seus binóculos (câmera subjetiva), termina por visualizar o protagonista de Janela indiscreta que está, assim como no filme, sentado dentro do quarto, com a perna quebrada e binóculos à mão, observando tudo o que se passa ao redor. Neste momento, pode-se perceber que há uma subversão na focalização da narrativa, o que faz com que passe a existir uma inversão de papéis: Bart, que até então era quem observava e imaginava que seu vizinho havia assassinado a esposa, tem na transposição do personagem Jeff, do filme de Hitchcock, para o seriado, não só um cúmplice da testemunha do suposto crime, como, ao mesmo tempo, pode estar sendo, ele mesmo, objeto da observação de Jeff.

Esta nova situação apresentada insere Bart of Darkness dentro de outra narrativa, a de Janela indiscreta, como se o espectador estivesse a observar um jogo de espelhos em que a história que se 
passa em Springfield (cidade onde vive a família Simpson) fosse uma subnarrativa semelhante à narrativa hipotextual - a do filme. O espectador tem então a impressão momentânea de que o episódio de Os Simpsons poderia estar ocorrendo dentro de Janela indiscreta, como uma história paralela à do crime do filme, porém refletindo-o ao revelar um protagonista semelhante ao da obra hipotextual e que se desenvolve de forma análoga.

Esta narrativa dentro da narrativa, ou tal uso de molduras narrativas, termina por questionar a relação entre o seriado e seus espectadores ao situar Jeff em meio à família Simpson. Agora, o protagonista de Janela indiscreta passa a ser um cúmplice do espectador, ao evidenciar que, como ele, alguém mais está a observar o que se passa com Bart. Ao se visualiza Jeff sentado em seu apartamento, o espectador não só passa a vê-lo, mas também a ver, sob um novo olhar, o que acontece com a família Simpson. Bart of Darkness, porém, ao não se estender neste argumento, tem o poder de proporcionar um rápido vislumbre dentro de tantas outras oportunidades que se insinuam durante o episódio, criando em sua plateia uma sede de revelação tão urgente quanto a que se encontra no filme de Hitchcock e no conto de Woolrich.

$\mathrm{O}$ uso de múltiplas molduras remete imediatamente a uma das mais sofisticadas cenas de enquadramento com molduras apresentada no filme Psicose (1960), também de Hitchcock. Nesta cena, é apresentada ao espectador a moldura da porta do quarto de um motel vista através de uma série de outras molduras, que incluem as das janelas do carro da protagonista, a qual está sentada ao volante e será assassinada na mesma noite. Essa técnica ajuda a estabelecer imageticamente uma distância necessária entre o texto e o espectador, que adentrará um mundo onde prevalecem o terror e a violência.

Em Bart of Darkness, um dos questionamentos que surge no espectador diz respeito à escolha do título do episódio de Os Simpsons. Por que este, ao invés de fazer alusão aos seus hipotextos, remete o espectador ao romance de Conrad (1999)? Uma das pos- 
síveis respostas surge em forma de generalização sobre os textos analisados. Neles, a inclinação do espectador leva-o a imaginar que a ausência da mulher (supostamente assassinada) traduz-se por "tinha que ser assassinato", o primeiro título do conto de Woolrich (2005), ressaltando a percepção negativa do ser humano sobre a realidade que o cerca. Este olhar pode ser realmente sombrio e violento, mas também apreendido com certa comicidade, resultando em produções como Bart of Darkness.

No romance de Conrad (1999), as atrocidades do Imperialismo Britânico são reais, enquanto que a suposta atrocidade no episódio de Os Simpsons é criada pelo imaginário do protagonista. Escritores como Hitchcock e Groening criam produções cuja crueldade imaginária predispõe-se a preencher espaços vazios, como se não bastassem os espaços já preenchidos por ela, fazendo, no entanto, uma varredura cômica, resultado das escolhas do roteirista ou diretor, principalmente ao criar um protagonista embusteiro e fantasioso. O diálogo entre o romance de Conrad (1999) e Bart of Darkness (1994) realiza-se, em última análise, ao perceber-se a violenta história da humanidade, continuamente camuflada, a erguer-se como pano de fundo para o imaginário - repleto de comicidade do episódio de Os Simpsons.

\section{Notes}

1. Título original: Heart of Darkness. Título traduzido: O coração das trevas. Tradução Celso M. Paciornik. São Paulo: Iluminuras, 2002.

2. Duas curiosidades interessantes: todas as tomadas do filme foram feitas do apartamento de Jeff, exigindo o maior cenário até então montado pela Universal Studios para um longa-metragem. Segundo, as versões do filme para televisão e 
vídeo, em virtude de disputa legal pelos direitos autorais iniciada por Cornell Woolrich, autor do conto "Rear window", não foram liberadas por mais de 30 anos.

3. Brian McFarlane (1996, p. 13) denomina de funções cardeais os pontos cruciais da narrativa transferidos no processo de adaptação de uma mídia a outra.

4. Segundo McFarlane (1996, p. 13), ao fazer-se um filme baseado em um texto, pode-se transferir ou adaptar elementos da narrativa textual. As transferências acontecem porque há elementos compatíveis às duas mídias.

5. Alternância, segundo McFarlane (1996, p. 200), acontece quando eventos geralmente opostos ocorrem simultaneamente ou paralelamente.

6. Índices integracionais, segundo McFarlane (1996), estão relacionados à caracterização subjetiva das personagens e à atmosfera da narrativa.

7. Nos contos "O barril de Amontilado" e "O gato preto" de Edgar Alan Poe, o protagonista empareda suas vítimas.

\section{Referências}

CONRAD, Joseph. Heart of Darkness. Nova York: Penguin Books, 1999

APOCALYPSE NOW. Francis Ford Coppola. Zoetrope Studios, 1979.

GENETTE, Gérard. Palimpsestos: literatura de segunda mão. Tradução Luciene Guimarães e Maria Antônia Ramos Coutinho. Belo Horizonte, 2003.

BART OF DARKNESS. The Simpsons. Criação: Matt Groening. Direção Jim Reardon. Lançamento $6^{\mathrm{a}}$ temporada (TV americana), 1994. 
JANELA INDISCRETA. Direção de Alfred Hitchcock. Paramount Pictures / Universal Pictures, 1954.

PSICOSE. Direção de Alfred Hitchcock. Shamley Productions, 1960.

MCFARLANE, Brian. Novel to Film: An Introduction to the Theory of Adaptation. Nova York: Oxford, 1996.

PERRONE-MOISÉS, Leyla. Texto, crítica, escritura. São Paulo: Ática, 1978.

WOOLRICH, Cornell. Rear Window. In: HARRISON, Stephanie (Ed). Adaptations: from Short Story to Big Screen. Nova York: Three Rivers Press, 2005.

Recebido em: 15/01/2014 Aceito em: 29/04/2014 